\title{
0 design emocional aplicado ao projeto gráfico de livros: projetando uma coleção de Agatha Christie
}

\author{
The emotional design applied \\ to book design: designing a \\ Agatha Christie collection
}

Alana Machado Kusma ${ }^{[1]}$, Ana da Rosa Bandeira ${ }^{[2]}$

Resumo: Este artigo apresenta os resultados de um estudo que explorou, por meio de revisão bibliográfica, as relações entre o design editorial de coleções e o design emocional. Esta foi a base teórica que substanciou a proposta do projeto gráfico de uma coleção de livros com obras selecionadas da autora Agatha Christie. A pesquisa foi complementada com a realização de um levantamento parcial das coleções de livros da autora anteriormente publicadas no Brasil e no exterior, com amostra definida por acessibilidade.

Palavras-chave: Design emocional. Design editorial. Coleções literárias. Agatha Christie.

Abstract: This article presents the results of a study that explored through literature review, the relationship between the graphic design of book collections and the emotional design. This was the theoretical basis that substantiated a proposition for the development of a book collection constituted of selected works by the author Agatha Christie. The research was complemented with a partial survey of the author's book collections previously published in Brazil and abroad, with a sample defined by accessibility.

Keywords: Emotional design. Editorial design. Literary collections. Agatha Christie.

[1] Bacharel em Design Gráfico, UFPEL. alanakusma@gmail.com

[2] Doutora em Comunicação e Informação, UFRGS. anaband@gmail.com 


\section{INTRODUÇÃO}

Este artigo tem por objetivo apresentar os resultados de um Trabalho de Conclusão de Curso realizado junto ao curso de Design Gráfico da Universidade Federal de Pelotas através do qual buscou-se aplicar as considerações apresentadas pelo autor Donald Norman (2008) a respeito do design emocional no design editorial de coleções, entendido principalmente a partir de Chico Homem de Melo (2006). Para tanto, foram elencados como objeto de estudo os romances policiais escritos pela autora Agatha Christie.

Detentora de uma extensa produção literária, a escritora foi escolhida pois, a partir de sua obra, identificou-se um problema possível de ser solucionado através do design gráfico, mais especificamente, através do design editorial. Constatou-se, por meio dos relatos das booktubers ${ }^{[3]}$ Duda Menezes $^{[4]}$ e Bel Rodrigues ${ }^{[5]}$, que muitos dos leitores interessados por adentrar no universo literário de Christie sentem-se intimidados ao deparar-se com a quantidade de livros por ela publicados e em dúvida sobre qual livro escolher para dar início à leitura. Norman (2008) defende que compreender o papel da emoção na relação complexa que temos com os objetos que possuímos é de grande importância para o designer. Assim, entende-se que a relevância da pesquisa proposta reside também na criação de um projeto gráfico que propicie uma boa experiência ao novo leitor de Agatha Christie aliada à curadoria dos títulos elencados para compor o escopo de pesquisa. Deste modo, foi definido o seguinte problema de pesquisa: "Como relacionar aspectos do design emocional e do design de coleções no projeto gráfico de capas para uma coleção de livros da Agatha Christie?".

O trabalho realizado caracterizou-se como uma pesquisa qualitativa de cunho exploratório na qual parte-se de uma revisão bibliográfica acerca dos temas que tratam a pesquisa, e um levantamento documental (GIL, 2008), das publicações da autora, buscando atender ao objetivo geral de desenvolver de forma prática o projeto gráfico das capas de uma coleção
[3] "pessoas que falam de livros e temas literários no YouTube" (CHERUBIN, 2017).

[4] Disponível em: https:// youtu.be/BMXYDUrvR3s. Acesso em: 11 abr. 2019.

[5] Disponível em: https:// youtu.be/X9hji1Pkuvo. Acesso em: 11 abr. 2019. 
de livros fundamentada no design emocional, que comunique ao leitor as características presentes nas obras selecionadas da autora Agatha Christie. Como objetivos específicos, realizaram-se ao longo do trabalho de conclusão de curso as seguintes etapas: a) apresentar a autora e o gênero literário em questão; b) fazer o levantamento de algumas coleções de livros da autora publicados no Brasil e no exterior, partindo especialmente de editoras que estão publicando atualmente seus livros; c) conceituar brevemente o design emocional; d) conceituar brevemente aspectos relacionados à coleções de livros; e) fundamentar teoricamente a relação entre o design emocional e editorial; f) selecionar os títulos que compõem a coleção empreendida e definir os conceitos que norteiam o projeto gráfico, alinhados ao referencial teórico definido; g) realizar o projeto gráfico de capas para uma coleção de Agatha Christie.

Com este artigo, pretende-se expor resumidamente as etapas que constituem a pesquisa teórica e apresentar os resultados da prática projetual resultante do estudo.

\section{AGATHA CHRISTIE - A RAINHA DO CRIME}

Nascida em 15 de setembro de 1890 em Torquay, Inglaterra, Agatha Mary Clarissa Miller mostrou interesse pela literatura desde jovem. Teve seu primeiro romance policial, O misterioso caso de Styles (no original, The Mysterious Affair at Styles), publicado em 1920 (PRATES, 2016). Sua estréia ocorreu no período destacado por Curran (2010) como a era de ouro dos romances policiais, compreendido entre os anos de 1920 e 1945. Este gênero literário que teve origem na Inglaterra da metade do século XIX, ganhou popularidade no meio século que se seguiu, principalmente, em razão da publicação seriada em impressos de baixo custo e do aumento na população alfabetizada no país (HUMPHERYS, 2017; TAUNTON, 2014).

Com um repertório de conhecimentos adquiridos no período em que atuou como enfermeira em um hospital da Cruz Vermelha na Primeira Guerra Mundial e nas inúmeras viagens realizadas durante sua vida, Christie criou diversas 
histórias contendo personagens que se tornaram icônicos, como o detetive belga Hercule Poirot e a detetive amadora Miss Jane Marple (CHRISTIE, c1977; CURRAN, 2010). Ao longo de sua carreira, a autora que ficou conhecida como a Rainha do Crime, publicou um total de 66 romances policiais, 20 peças de teatro, 6 romances sob o pseudônimo de Mary Westmacott e mais de 150 contos, e teve ainda diversas de suas obras adaptadas para o cinema e para a televisão (PRATES, 2016).

A Agatha Christie Limited ${ }^{[6]}(\mathrm{ACL})$, sobretudo nos últimos anos, tem buscado inserção no mercado audiovisual autorizando a adaptação de vários livros e peças populares de Christie. No que diz respeito ao espólio literário da autora, em 2019, a ACL renovou o contrato que garante à HarperCollins Publishers os direitos de publicação mundial da autora na língua inglesa até 2030. Em parceria com a HarperCollins não só foram relançados os títulos originais da autora, mas, em 2014, 2016 e 2018, a autora Sophie Hannah foi comissionada para escrever três novos romances que retomam o personagem Hercule Poirot (THE HOME OF AGATHA CHRISTIE, 2019).

Sendo assim, as ações da ACL demonstram o desejo de manter a obra de Agatha Christie atual, mais do que isso, mostram a preocupação em reforçar a imagem da autora como marca e continuar a conquistar novos leitores, captando a atenção do público jovem. Observa-se que muito da literatura de ficção direcionada para este público, hoje baseia-se em sagas e trilogias literárias que orientam o leitor a consumir livros organizados em coleções. Alguns exemplos dessa prática são: a saga Harry Potter (1997-2007) escrita por J. K. Rolling, a saga Crepúsculo (2005-2008) escrita por Stephenie Meyer, a trilogia Jogos vorazes (2008-2010) escrita por Suzanne Collins e, no gênero romance policial, a trilogia The game (2010-2012) escrita por Anders de la Motte.

Deste modo, entende-se que ao projetar uma coleção literária com a obra de Agatha Christie é preciso realizar uma curadoria dos títulos, de maneira que a seleção tenha apelo para público que se objetiva.
[6] Empresa fundada, em 1955, com intuito de gerenciar os direitos de publicação, reprodução e adaptação das obras de Agatha Christie em uma escala mundial (AGATHA CHRISTIE LTD, 2019). 


\subsection{UM BREVE LEVANTAMENTO DE}

\section{COLEÇÕES PUBLICADAS DA AUTORA}

Para melhor compreender o alcance de Agatha Christie e futuramente fornecer referências para o projeto prático, foi feito um breve levantamento por acessibilidade (GIL, 2008) de algumas coleções de livros da autora publicadas no Brasil, Reino Unido e Estados Unidos. Em um primeiro momento, optou-se por utilizar como recorte informações a respeito das editoras que, no período de realização da pesquisa, estavam publicando os títulos de Agatha Christie no Brasil, que são: a Folha, a HarperCollins Brasil, a Globo Livros, e a L\&PM. Fez-se tal recorte visando evidenciar as escolhas editoriais e o tratamento gráfico conferido às obras da autora em âmbito nacional nos últimos anos, visto que, este é o contexto no qual se insere o projeto prático proposto.

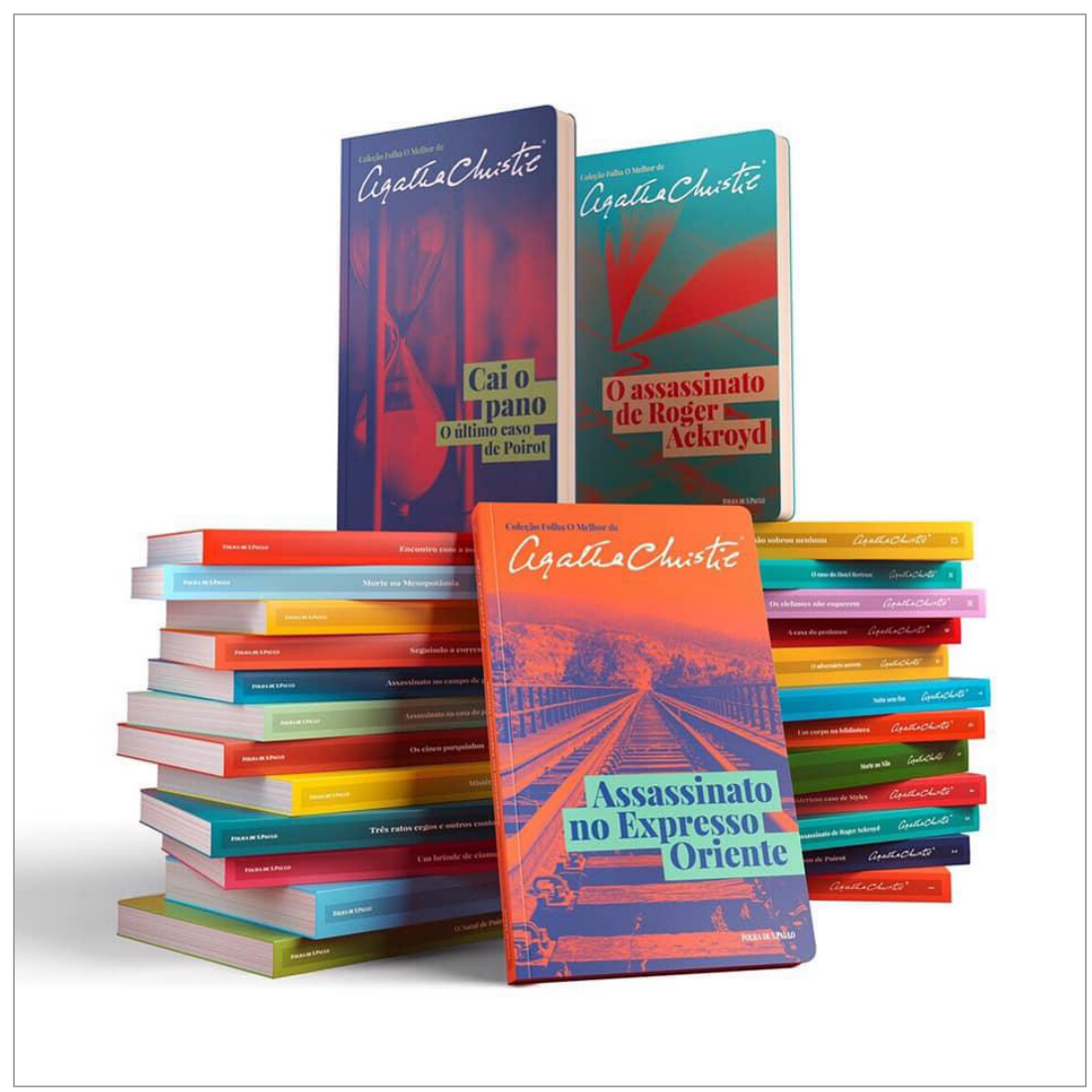

Figura 1 - Imagem de divulgação do lançamento da Coleção Folha o Melhor de Agatha Christie, 2019. Fonte: www. facebook.com/FolhaColecoes/ posts/1159356614270932. Acesso em: 26 set. 2019. 
A Folha lançou, entre os meses de junho a novembro de 2019, uma coleção contendo 24 títulos de Agatha Christie em formato brochura (Figura 1), que puderam ser comprados individualmente em bancas de revistas ou encomendados através do site. Em um dos textos publicitários que divulgam o lançamento explica-se que

[...] as 24 obras escolhidas para essa coleção foram selecionadas visando levar ao leitor as primeiras produções de Agatha Christie, que datam da década de 1920, até as de 1960. Com esse recorte temporal, a Coleção Folha o Melhor de Agatha Christie permite que novos leitores tenham contato com os principais títulos e personagens da autora, pois abrange enredos protagonizados e minuciosamente investigados pelo memorável detetive Hercule Poirot e também pela notável Miss Marple, ambas figuras intrinsecamente ligadas à produção da autora (COLEÇÃO FOLHA O MELHOR DE AGATHA CHRISTIE, 2019, s. p., grifo do autor).
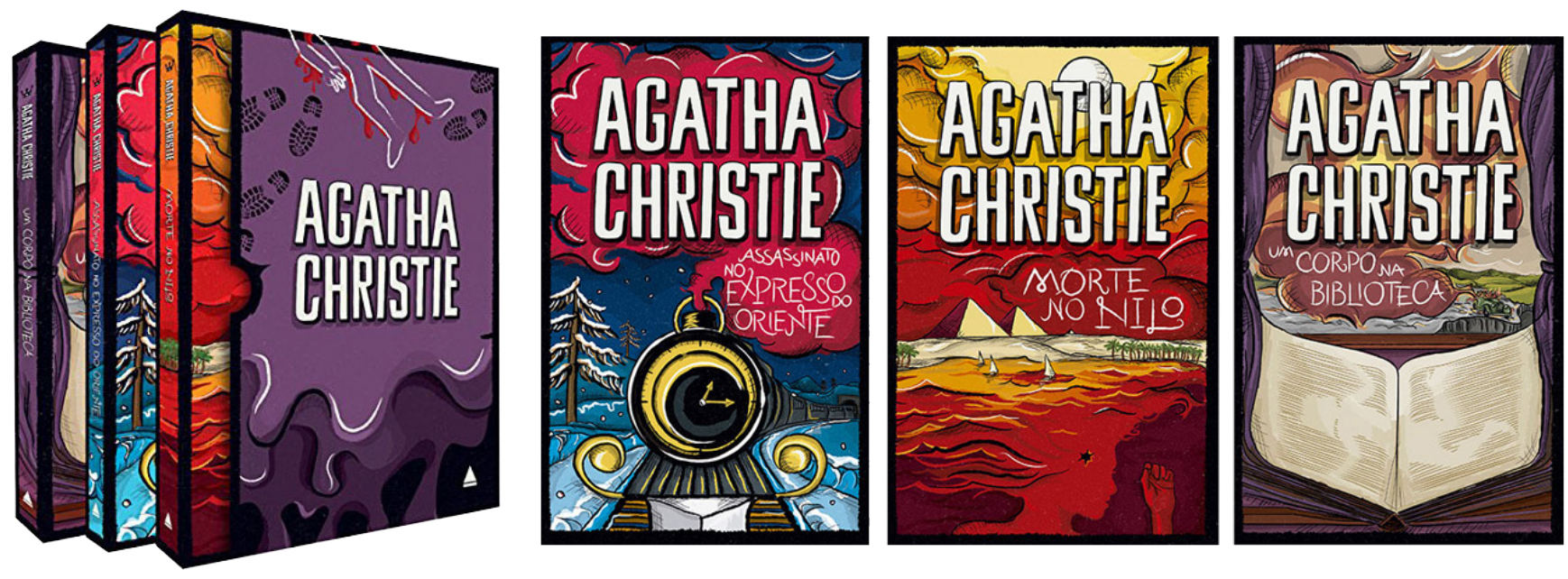

Figura 2 - Box 1 e capas dos três livros que o compõem, lançado pela Nova Fronteira, 2014. Fonte: sobrecapas.blogspot.com/2015/o7. Acesso em: 1 set. 2019. 
A HarperCollins Brasil, ramo brasileiro da HarperCollins Publishers, tem publicado a obra da autora em boxes contendo três livros cada, e ao todo, de 2014 a 2019, publicou 24 títulos no formato capa dura.

A coleção, inicialmente desenvolvida e lançada pelo selo Nova Fronteira (Figura 1), teve os primeiros dois boxes projetados pelo Maquinária Studio. Renata Sturm (apud MACHADO, 2015b), editora responsável pelo projeto, explica que para a sua realização foram feitas diversas reuniões, ao longo de meses, com a equipe do Maquinária Studio para a definição e aprovação dos aspectos da proposta.

Nosso primeiro objetivo com o novo projeto gráfico para Agatha Christie era de reapresentá-la com um jeito mais pop. A autora é um clássico do policial e suspense, mas existe uma nova geração que nunca leu a Rainha do Crime ou está descobrindo essa incrível autora só agora porque autores atuais citam Agatha como sua principal referência. A Nova Fronteira tem mais de 70 obras da autora no catálogo, nos sentimos na obrigação de trazê-la à tona novamente da maneira que ela merece. E o projeto gráfico teve papel essencial nesse processo (STURM apud MACHADO, 2015b, s.p.).

Com esta coleção pretendia-se alcançar dois públicos alvos distintos: os considerados novos leitores, de faixa etária entre 25 e 35 anos, e os fãs antigos de Agatha Christie. Além do foco nesses nichos, observou-se o aumento nas vendas para jovens de 15 a 18 anos, atribuído por Sturm, à paleta de cores usada, à ilustração exclusiva e à atratividade que os boxes têm no ponto de venda (apud MACHADO, 2015b).

A Globo Livros, licenciada desde 2001, publicou em 2014 uma coleção de Agatha Christie com oito volumes em formato brochura (Figura 3). Em 2019 foram adicionados outros três títulos à coleção.

Ana Lima Cecílio (apud MACHADO, 2015a, s. p.), editora da Globo Livros, fala sobre os critérios para a escolha de alguns dos títulos publicados: 

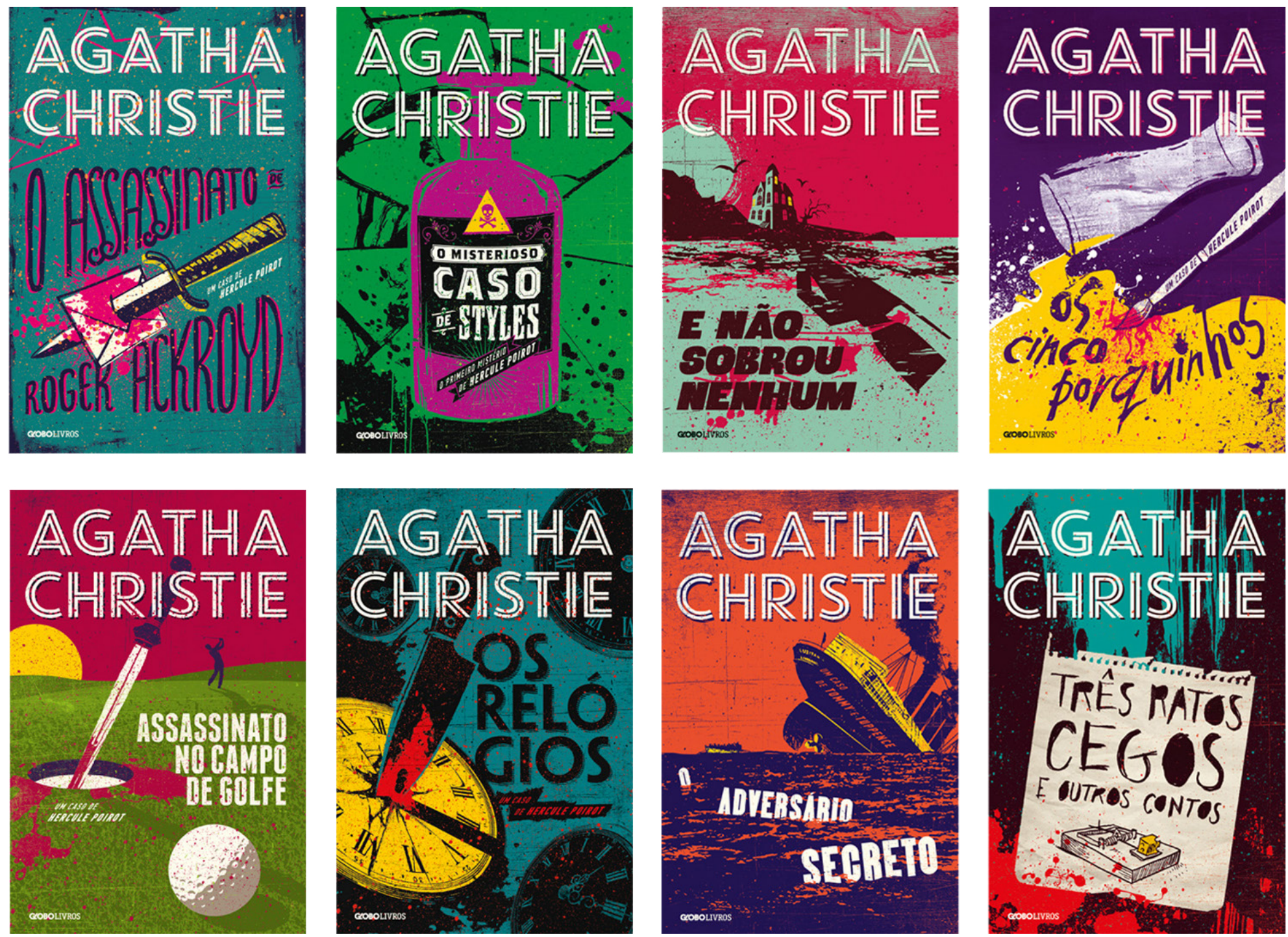

Figura 3 - Capas dos oito livros que compõem a coleção da Globo Livros, 2014. Fonte: sobrecapas.blogspot.com/2015/o2/. Acesso em: 1 set. 2019.

CC [...] escolhemos E não sobrou nenhum (o antigo O caso dos dez negrinhos) por ser considerado em diversas listas o melhor livro de suspense de todos os tempos; escolhemos O misterioso caso de Styles por ser o primeiro livro da Agatha (e portanto o primeiro livro com o Poirot); escolhemos Três ratos cegos e outros contos por conter o conto que foi a origem de A ratoeira, a peça que está no Guiness como a mais longeva da história, ainda hoje em cartaz em Londres; escolhemos $\mathrm{O}$ assassinato no campo de golfe por ter uma célebre adaptação para o cinema - e assim por diante.

O designer e ilustrador Rafael Nobre foi o responsável pela criação das capas dos oito primeiros livros. O projeto foi construído levando em consideração algumas diretivas, são elas: apre- 
sentar algum elemento presente na capa também na lombada e contracapa; insinuar a arma do crime quando esta for específica; utilizar na capa imagem que remeta à história favorecendo objetos e lugares sem focar em rostos (MACHADO, 2015a).

Nobre (apud MACHADO, 2015a, s.p.) relata que "O maior desafio foi não repetir uma solução já criada, pois há muitas edições tanto nacionais como internacionais dos livros da Agatha com as mais distintas abordagens". Ele explica, ainda, que buscou referência na Coleção Amarela da Livraria Globo de Porto Alegre, na qual foram publicados alguns dos primeiros livros de Agatha Christie no Brasil, conta que buscou inserir algum elemento amarelo nas capas como forma de resgatar a história da autora com a Globo Livros.
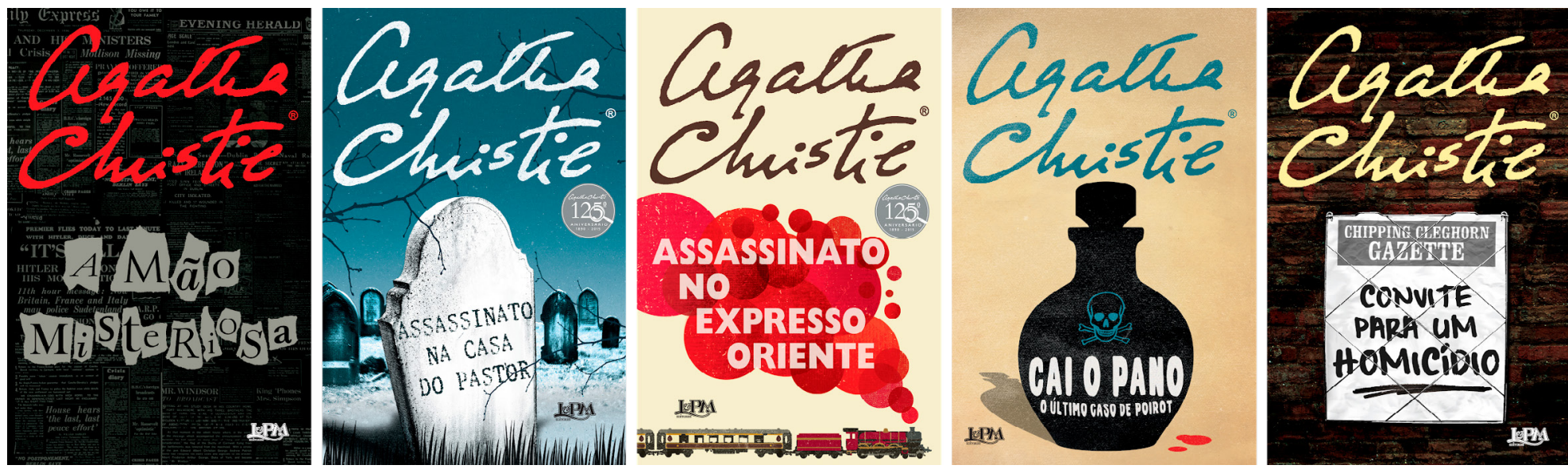

Figura 4 - Algumas capas de livros de Agatha Christie no catálogo da L\&PM. Fonte: www.lpm.com.br. Acesso em: 22 set. 2019.

A L\&PM tinha em seu catálogo, no momento em que foi realizada a pesquisa, 96 títulos da autora, isto considerando apenas o formato pocket. A Figura 4 exemplifica alguns deles.

David Wardle, designer e ilustrador britânico, foi o responsável pelo projeto das capas inicialmente criadas para a HarperCollins UK e que, mais tarde foram compradas pela L\&PM para a publicação no Brasil. Em entrevista ao blog da L\&PM 
Editores (2014) Wardle conta que para projetar as capas inspirou-se em antigos cartazes ferroviários e pôsteres underground dos anos 1950, populares no Reino Unido, e também nas ilustrações de Walter Spradbery.

Desta maneira, as coleções brevemente expostas, juntamente com os comentários feitos pelas editoras e pelos designers envolvidos, ilustram a popularidade de Agatha Christie e sua presença no cenário editorial nacional, ao mesmo tempo em que reforçam a relevância do trabalho proposto. Destaca-se ainda que a pesquisa por coleções da autora resultou em inúmeros projetos tanto nacionais quanto do exterior que perpassam diversas décadas. No Trabalho de Conclusão de Curso no qual este artigo origina-se estas coleções foram referenciadas ao longo do trabalho para exemplificar as teorias expostas e também como referência visual para a elaboração da prática projetual.

\section{DESIGN EMOCIONAL E 0 DESIGN EDITORIAL DE COLEÇÕES}

Norman (2008) expõe suas considerações a respeito da influência que as emoções têm nos processos de tomada de decisão, como elas impactam na relação das pessoas com os objetos e como, por consequência, impactam àqueles que os idealizam, os designers. Baseando-se em estudos acerca dos mecanismos cerebrais que regem o comportamento humano e da forma como indivíduos reagem aos estímulos de seu ambiente, ele caracteriza

[...] três diferentes níveis de estruturas do cérebro: a camada automática, pré-programada, chamada de nível visceral; a parte que contém os processos cerebrais que controlam o comportamento quotidiano, conhecida como nível comportamental; e a parte contemplativa do cérebro, ou nível reflexivo (NORMAN, 2008, p. 41, grifo do autor).

Estes processos desempenham papéis diferentes, mas atuam em conjunto e interagem entre si de modo complexo (NORMAN, 2008). Tendo em vista os diferentes níveis de estrutura do cérebro, Norman (2008) os correlaciona com a 
prática do design, assim identificando quais seriam as características de projeto necessárias para atender a cada nível.

O design para o nível visceral é centrado na aparência, a estética do produto é importante pois é nesta etapa que se formam as primeiras impressões. $O$ design comportamental foca na experiência de uso do produto e requer atenção quanto à função, ao desempenho e à usabilidade. Já o design reflexivo trabalha com o subjetivo e com as emoções mais complexas buscando criar significado, evocar memórias e despertar sentimentos. Contudo, o próprio autor atesta que, apesar de útil no desenvolvimento de projetos, a sistematização elaborada por ele é bastante simplificada em vista da complexidade da emoção humana (NORMAN, 2008).

Isto posto, uma vez que, objetivou-se a apropriação destes conceitos sob a ótica do design editorial de coleções de livros, fez-se necessária a apresentação do aporte teórico acerca deste tipo de projeto gráfico, a fim de substanciar a relação que se procurou estabelecer entre ambos.

Neste âmbito, tomou-se como referência principal, para compreender teoricamente o tema, as noções expostas por Chico Homem de Melo (2006) que caracteriza a coleção de livros do ponto de vista do projeto gráfico, como o equilíbrio entre os elementos variáveis e invariáveis (fixos) a ele aplicados. O autor argumenta que estes elementos devem ser trabalhados de modo a conferir ao conjunto de livros uma identidade que exiba unidade visual, mas que, ao mesmo tempo, permita que cada volume possa ser percebido individualmente.

Para além da pesquisa apresentada até então, buscou-se discutir os pontos de convergência entre os dois campos abordados no trabalho.

\subsection{O DESIGN EMOCIONAL APLICADO AO PROJETO DE COLEÇÕES LITERÁRIAS}

Para estabelecer relações com o design emocional pensou-se, inicialmente, a respeito dos aspectos gráficos das principais partes que compõem o livro. A primeira consideração feita é de 
que a capa, em um primeiro momento, estimula o nível visceral, uma vez que, ela pode ou não despertar o interesse do leitor. Esta reação é posteriormente mediada pelo nível reflexivo que racionaliza o que foi registrado e avalia se o livro trata de um assunto que lhe interessa ou não (NORMAN, 2008; SEHN, 2009).

Carvalho (2008, p. 32) diz que "a capa condensa numa única imagem a personalidade do livro", Haslam (2010, p. 160) refere-se à capa como sendo "uma promessa feita pela editora, em nome do autor, para o leitor" e destaca que uma de suas funções é a de indicar o conteúdo. Assim, entende-se que há convenções estéticas definidas para cada gênero literário que geram no leitor expectativas a respeito do conteúdo de um livro baseado na visualidade de sua capa. Portanto, a apreensão dos elementos no projeto gráfico de uma capa como símbolos de uma temática específica faz parte de uma linguagem construída pelas editoras e requer que o leitor esteja familiarizado, contudo não é fixa, pode mudar de acordo com a cultura e com o passar do tempo. Ainda nesse sentido, as capas têm o potencial de se tornarem símbolos, na medida em que se consolidam na memória do público em decorrência de uma interação prolongada (CARVALHO, 2008; NORMAN, 2008; SEHN, 2009).

Relativo ao interior do livro, Norman (2008, p. 44) afirma que o prazer de ler uma obra literária "se origina do nível reflexivo e exige estudo e interpretação". Embora essa declaração seja verdadeira, pode-se considerar também que, do ponto de vista do design, o ato mecânico da leitura está relacionado com o nível comportamental, pois é necessário que haja certa clareza no layout e que as tipografias empregadas ofereçam legibilidade e leiturabilidade para que o leitor tenha uma experiência agradável. Ainda pode-se destacar fatores como a adequação do formato do livro, o tipo de papel, a qualidade da impressão e a resistência da encadernação. Todas estas características somadas impactam na satisfação do leitor ao utilizar o livro. 
Em contrapartida, com a criação de uma diagramação fora dos padrões tradicionais, como palavras sobrepostas ou tipografias com baixa legibilidade, pode-se provocar sentimentos de frustração e de confusão, ou ainda, induzir o leitor a interagir com a página, fazendo-o, por exemplo, rotacioná-la para que possa ler o texto. Nesses casos, o intuito é causar no leitor uma reação do nível reflexivo, onde a dificuldade no uso do livro no senso convencional tem por objetivo fazer com que ele reflita a respeito das ideias expressas pelo autor do texto. Assim, o projeto gráfico da publicação pode - e provavelmente vai - afetar a maneira como o leitor vai interagir com a obra, ampliando o sentido da mesma.

As coleções de livros enquanto objetos despertam o interesse por conta de sua materialidade, da apresentação visual, dos materiais e da experiência tátil que eles oferecem. Pode-se considerar que o sentimento de realização por ter todos os títulos de uma coleção vem de um processo reflexivo, mas responde a uma reação visceral, a preferência humana pela simetria. Outro aspecto ligado ao nível reflexivo a ser observado é o apelo de ter uma coleção de livros, ou várias, decorando a estante, por exemplo, seja para satisfação pessoal ou como parte da construção de uma personalidade que se deseja exibir para os outros (NORMAN, 2008; SEHN, 2009).

Com exceção daquelas coleções idealizadas pelos autores em forma de trilogia ou saga, a publicação de uma coleção é organizada com base em critérios editoriais, através dos quais busca-se apresentar ao público uma seleção de livros inéditos ou já conhecidos. Nesse sentido, identifica-se que é possível abordar o trabalho de um autor de diferentes maneiras: a publicação de sua bibliografia na íntegra; a publicação de uma parte de sua obra selecionada com base em critérios específicos, como um recorte temporal ou uma seleção dos melhores livros, e ainda a inserção de alguns títulos em uma coleção temática juntamente com obras de outros autores.

A maneira como são selecionados os títulos de uma coleção assume maior importância quando se aborda uma au- 
tora como Agatha Christie, já bastante conhecida e que teve seu trabalho publicado inúmeras vezes. Segundo Norman (2008), o nível reflexivo está também ligado à cultura, por isso é pertinente considerar que Christie foi publicada em décadas passadas, no Brasil, para um público leitor culturalmente diferente do atual. Suas histórias, embora muitas vezes protagonizadas por um mesmo personagem, são de certa forma independentes e podem ser lidas em uma ordem que não necessariamente obedece à ordem cronológica de publicação.

Hoje, a maioria das coleções que têm como público-alvo os jovens leitores, são lançadas em uma ordem cronológica na qual todos os volumes fazem parte de um arco narrativo. Por esse motivo surge a preocupação de que novos leitores de Agatha Christie possam sentir-se intimidados ao se deparar com a obra da autora pela primeira vez, e cabe então ao designer pensar estratégias para torná-la mais acessível aos públicos mais jovens, levando em consideração a lógica de mercado através da qual as coleções são lançadas atualmente. É nesse sentido que a coleção projetada, busca operar.

\section{PROJETO PRÁTICO}

Como desdobramento da pesquisa teórica realizada, teve-se por objetivo o desenvolvimento do projeto gráfico de capas para uma coleção de livros de Agatha Christie. Desta forma, elaborou-se uma proposta que, ao mesmo tempo que adequa-se à teoria do design emocional (NORMAN, 2008), visa atender ao público pretendido: jovens na faixa etária de 15 a 25 anos, delimitada, principalmente, a partir do relato de Sturm (apud MACHADO, 2015b), que possuam afinidade com o gênero romance policial, mas que nunca tenham lido os livros de Agatha Christie por se sentirem confusos ou intimidados diante da quantidade de obras publicadas da autora.

Com isso, foi idealizada uma coleção comemorativa dos 130 anos da autora, celebrados em 2020, contendo dois livros acompanhados de um infográfico. A escolha dos títulos baseou-se em uma divisão temática por personagem e to- 
mou-se como referência a categorização apresentada no site oficial da autora (THE HOME OF AGATHA CHRISTIE, 2019). Assim, optou-se por apresentar ao leitor os dois personagens de maior destaque na obra de Agatha Christie: Hercule Poirot protagonizando O misterioso caso de Styles e Miss Marple que aparece pela primeira vez em Assassinato na casa do pastor. Juntos, todos os livros protagonizados pelos dois personagens constituem mais da metade da obra da autora.

O infográfico que acompanha os dois livros contém uma linha do tempo dos livros de Christie publicados no Brasil, bem como uma breve apresentação de seus principais personagens e algumas curiosidades sobre a autora e suas obras e uma listagem indicando os seus títulos favoritos.

Assim, com a proposta elaborada, coloca-se à disposição do leitor recursos que permitem a ele uma visão geral da obra de Agatha Christie, conferindo-Ihe autonomia para explorar o trabalho da autora e escolher o "caminho" que quer tomar. Ainda que a coleção seja formada por apenas dois volumes, ou seja, dois caminhos possíveis de adentrar nas obras da autora, o infográfico que a acompanha constitui uma ferramenta que permite ir além dos limites do produto oferecido. Entende-se que desta forma cria-se um produto com apelo ao nível reflexivo (NORMAN, 2008).

Levando em consideração que não há uma metodologia de projeto específica que oriente o desenvolvimento de coleções literárias, tomou-se como base a metodologia projetual de Bruce Archer, citada por Rodolfo Fuentes (2006, p. 30) na qual o processo de desenvolvimento do projeto divide-se em três grandes fases: analítica, criativa e executiva. Contudo, foram realizadas adaptações, de modo que a metodologia escoIhida servisse às especificidades do tipo de projeto elaborado.

Deste modo, em um momento inicial, ateve-se ao levantamento de capas realizado previamente com o intuito de observar o que já havia sido apresentado, em termos de projeto gráfico, nas capas dos dois títulos selecionados. As capas foram organizadas em quadros e segmentadas por 
país de origem e por ordem cronológica de publicação ${ }^{[7]}$. Buscando contextualizar as informações gráficas observadas efetuou-se a leitura de 0 misterioso caso de Styles e Assassinato na casa do pastor.

Assim, foi possível identificar os objetos, cenas e personagens presentes nas narrativas, que foram utilizados para representar a história nas capas de ambos os títulos. Bem como, foi possível elencar pontos comuns a respeito dos projetos gráficos e da maneira como foram organizadas as informações. Na maioria das capas levantadas é feito o uso de imagem, seja esta uma ilustração ou uma fotografia, embora a relação entre texto e imagem se configure de formas bem distintas. Em alguns casos, a informação textual apresenta-se completamente destacada da imagem, já em outros casos esta informação integra-se com a ilustração completando o seu sentido. Em contrapartida, poucas são as capas compostas somente por tipografia e elementos gráficos de apoio. Já no que diz respeito à hierarquia da informação textual, de modo geral, observa-se que especialmente nas publicações feitas a partir dos anos de 1980, tanto no Brasil como no exterior, é conferido maior destaque ao nome da autora do que ao título da obra. Também identificou-se em diversas das capas o uso de alguma menção ao protagonista da história. Em relação às cores, não há uma recorrência de padrões cromáticos que possa ser estabelecida para nenhum dos títulos.

Foi a partir das análises, aqui resumidas, em adição à pesquisa efetuada anteriormente no trabalho, que elencaram-se informações importantes e os elementos desejáveis a compor as peças gráficas do projeto prático, os quais são expressos na sequência juntamente com a apresentação dos resultados obtidos na criação das peças gráficas.

Ao considerar quais seriam os elementos gráficos e as informações de destaque na hierarquia visual das capas (LUPTON, 2008), optou-se por uma abordagem que referencia visualmente o período em que os livros foram originalmente escritos e lançados, resgatando elementos de época
[7] Os quadros elaborados a partir do levantamento realizado podem ser consultados no link https://bit.ly/3385Vuv. 
relacionados ao objeto desta pesquisa (FUENTES, 2006). Para tanto, colocou-se a tipografia como elemento principal da capa, tomando como referência os livros publicados no início do século XX (HASLAM, 2010). A ilustração foi inserida no projeto, pois julgou-se pertinente o apontamento de Sturm (apud MACHADO, 2015b) a respeito da coleção lançada pela HarperCollins Brasil, em 2014, indicando a ilustração como um dos elementos que capta o interesse do público jovem. A isto, aliou-se a percepção de que os objetos relacionados à trama são frequentemente representados nas capas de edições lançadas anteriormente.

Entendeu-se que a ilustração, além de ser um recurso que chama a atenção do público, é um elemento que contribui para a percepção da identidade particular de cada livro, constituindo um elemento variável entre os volumes da coleção. Quanto aos demais elementos variáveis e invariáveis (MELO, 2006), fixou-se a tipografia e a posição das informações textuais como elementos invariáveis, já a tipografia do nome do livro e a cor constituem os elementos variáveis, sendo a cor a principal responsável por gerar a diferenciação de um volume para o outro.

Uma vez que os volumes não são numerados, identificou-se a necessidade de incluir as frases o primeiro caso de Hercule Poirot e O primeiro caso de Miss Marple, respectivamente, nas capas de 0 misterioso caso de Styles e de Assassinato na casa do pastor, de modo a situar o leitor a respeito de qual personagem é o protagonista de cada história.

Assim, as Figuras 5 e 6 exibem, respectivamente, o projeto finalizado das capas de 0 misterioso caso de Styles e de Assassinato na casa do pastor.

Em ambas as capas, utilizou-se um layout, em que os elementos textuais são dispostos centralizados e o título é emoldurado lateralmente por ilustrações espelhadas. Esta organização foi pensada como uma referência às publicações do início do século XX (HASLAM, 2010; MEGGS, 2009). Em O misterioso caso de Styles a moldura é formada pelo desenho de 
Caía a madrugada na casa de campo de Styles quando moradores e convidados acordaram com os barulhos vinclos clo quarto de Emily Inglethorp, a proprietária da mansão.

Aparentemente, ela estava sofrendo um ataque cardiaco, mas ninguém podia ajudá la de imediato porque o cômodo estava trancado.

Quando John e Lawrence, entea: dos dela, e o capitão Hastings, amigo da família, conseguiram derrubar a porta, a matriarca sofria convulsōes. Morreu instantes depois. Não demorou para que o médico passasse a suspeitar de assassinato por envenetar de ass
namento.

Livro de estrein de Agatha Chite "O misterioso caso Styles", de 1920 , apresenta operStyles, de 1,20, apresenta o pernas décadas seguintes, o sagaz Hercule Poirot.

Com o apoio de Hastings, o minucioso detetive belga busca desvendaro intrincado caso. Era o primeiro de muitos mistérios que viriam pela frente.<smiles>c1ccccc1</smiles>
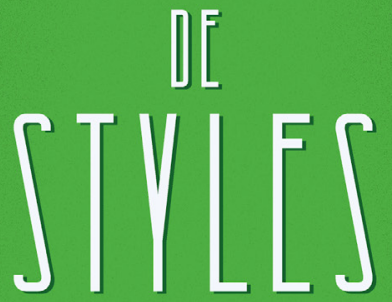

AGATHA CHRISTIE
Figura 5 - Capa de 0 misterioso caso de Styles. Fonte: dados da pesquisa.

Figura 6 - Capa de Assassinato na casa do pastor. Fonte: dados da pesquisa.
Num dia de calmaria em St Mary Mead o famoso vilarejo criado por Agatha Christie, o pastor Leonard Clement e Miss Marple falam sobre as intrigas sempre presentes nas rodinhas de conversa do lugar.

"Receio muito que após observar a natureza humana durante t tanto tempo, como eu, a gente nao espere muito dela. Concordo que o mexerico é errado e não é bondoso, mas e sempre verdade, nao er" Publicado em 1930, "Assassinato na casa do pastor" marca a esMarple na literatura de Agatha Christie. Muito curiosa e atenta a personagem de cabelos brancos apareceria em outros 11 romances de autora inglese Neste livro. Miss Marple é desafiada a descobrir quem matous fracta a descobrir querm matou o coronel Protheroe, um homem odiado por mL

E não só isso: por que, afinal, o corpo estava estendido no escri-

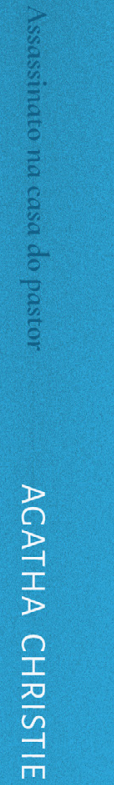

ASSASSINATO NA

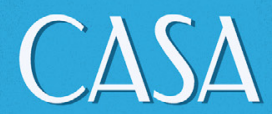
DO

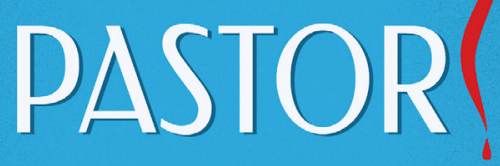


duas xícaras inclinadas das quais se derrama um líquido, este elemento foi escolhido pois trata-se da possível arma do crime na trama. Já em Assassinato na casa do pastor, o elemento ilustrado é um vidro de tinta para caneta bico de pena, este faz referência ao momento do crime, pois a vítima é alvejada enquanto escreve uma nota sentada à beira da escrivaninha. Em lugar do layout centralizado, na contracapa, optou-se por uma abordagem mais contemporânea, dividindo a área em duas colunas: a da direita ocupada pela sinopse e a da esquerda por uma ilustração que remete à ilustração presente na capa. Na porção inferior, centralizados em relação às colunas colocou-se à direita o código de barras acompanhado do ISBN e à esquerda o logotipo da editora HarperCollins.

As tipografias selecionadas para o nome de cada um dos livros, Architectural (Figura 7) para O misterioso caso de Styles e Federo (Figura 8) para Assassinato na casa do pastor, assemeIham-se com as formas características do movimento Art déco, portanto foi através das escolhas tipográficas que buscou-se mais fortemente referenciar os anos de 1920 e 1930, décadas de lançamento dos livros trabalhados e também período de atuação do movimento em questão (MEGGS, 2009; LUPTON, 2008). Os nomes foram formados alterando-se a escala das palavras de modo a criar uma composição visual mais atraente.

\section{ARCHIIECTURAL}

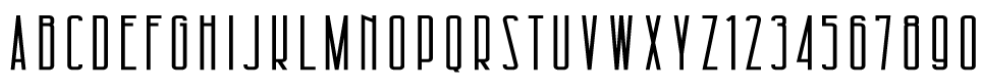

\section{Federo}
ABCDEFGHIJKLMNOPQRSTUVWXYZ abcdefghijklmnopqrstuvwxyz1234567890

Figura 7 - Tipografia Architectural. Fonte: Acervo pessoal.

Figura 8 - Tipografia Federo. Fonte: fonts.google.com/specimen/ Federo. Acesso em: 24 nov. 2019. 
As cores que foram selecionadas para O misterioso caso de Styles baseiam-se na planta origem do veneno utilizado como arma do crime na história, a Estricnina, que é obtida da semente da Strychnos nux-vomica, árvore de folhagem verde e com frutos de cor alaranjada. Para a capa de Assassinato na casa do pastor, optou-se por uma paleta de cores complementares: o vermelho simbolizando o sangue da vítima e o azul fazendo referência a tranquilidade da personagem Miss Marple (AMBROSE; HARRIS, 2009). Foram utilizadas cores saturadas com o objetivo de captar rapidamente a atenção do leitor no ponto de venda, provocando uma reação do tipo visceral (NORMAN, 2008). Foram empregadas, a fim de conferir uma sutil ilusão de profundidade às composições: uma cor mais escura do que aquela de fundo para alguns elementos textuais secundários, aplicação da cor branca nos títulos, adição de sombra projetada na tipografia dos títulos e adição de textura ótica granulada ao plano de fundo (DONDIS, 1997; LUPTON, 2008).

O tamanho pensado para os exemplares foi de $13 \mathrm{~cm}$ de largura por $21 \mathrm{~cm}$ de altura, dimensões que correspondem aproximadamente ao retângulo racional 1:1.6 (HASLAM, 2010). Além de garantirem um bom aproveitamento do papel na impressão em larga escala (RIBEIRO, 2003), estas dimensões permitem ao leitor fácil manuseio e conforto no momento da leitura, levando em consideração os aspectos ergonômicos, uma vez que o prazer e a efetividade no uso de um produto é destacado por Norman (2008) como um dos aspectos a serem contemplados quando pensa-se sob a ótica do design emocional.

Optou-se por produzir os volumes em capa dura pois trata-se de uma edição comemorativa e, portanto, é desejável que esta tenha um aspecto mais durável, instigando no leitor o desejo de colecioná-los (CARVALHO, 2008; NORMAN, 2008).

Na Figura 9 apresentam-se as vistas de capa e contracapa dos livros da coleção impressos e montados.

A Figura 10 mostra, o projeto finalizado do infográfico que acompanha a coleção. Tomou-se como referência para a elaboração desta peça o infográfico veiculado pelo site En- 

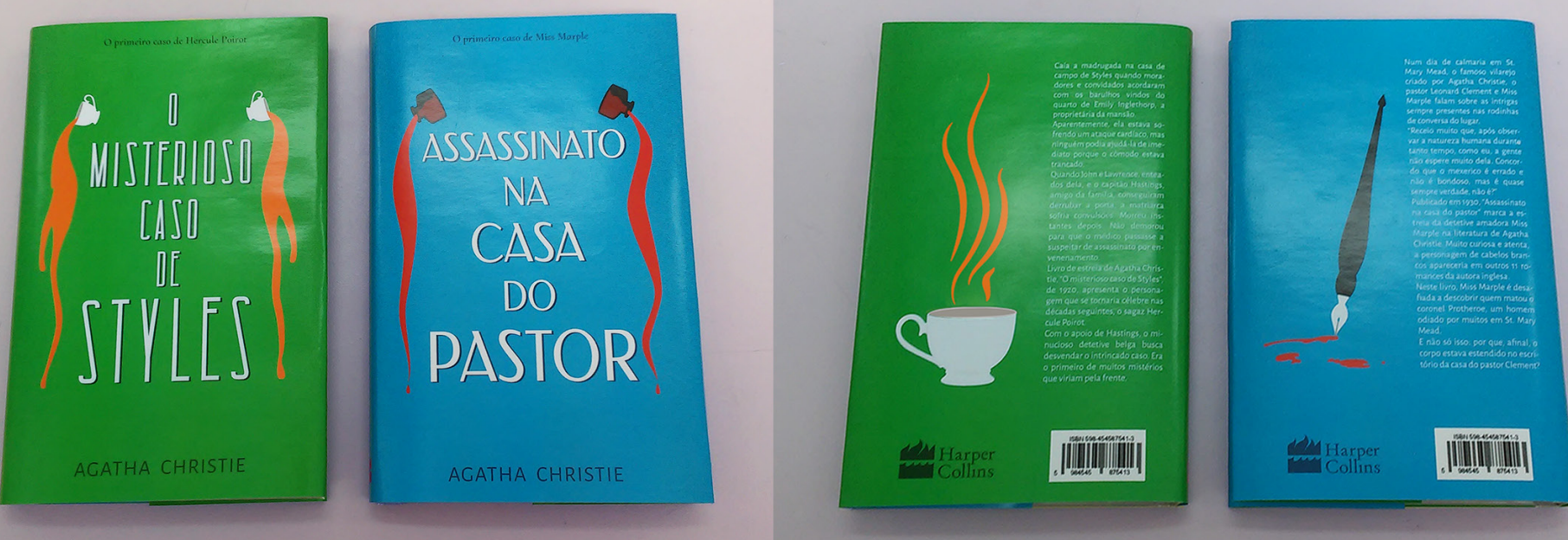

Figura 9 - Livros da coleção vista capa e contracapa. Fonte: dados da pesquisa.

tertainment Weekly ${ }^{[8]}$, em maio de 2017, acompanhando uma reportagem sobre a estréia do filme Assassinato no Expresso do Oriente. As informações que a compõem foram retiradas do infográfico de referência e do site oficial de Agatha Christie (THE HOME OF AGATHA CHRISTIE, 2019).
[8] ew.com/books/2017/05/08/ agatha-christie-binge.

Figura 10 - Infográfico finalizado. Fonte: dados da pesquisa.

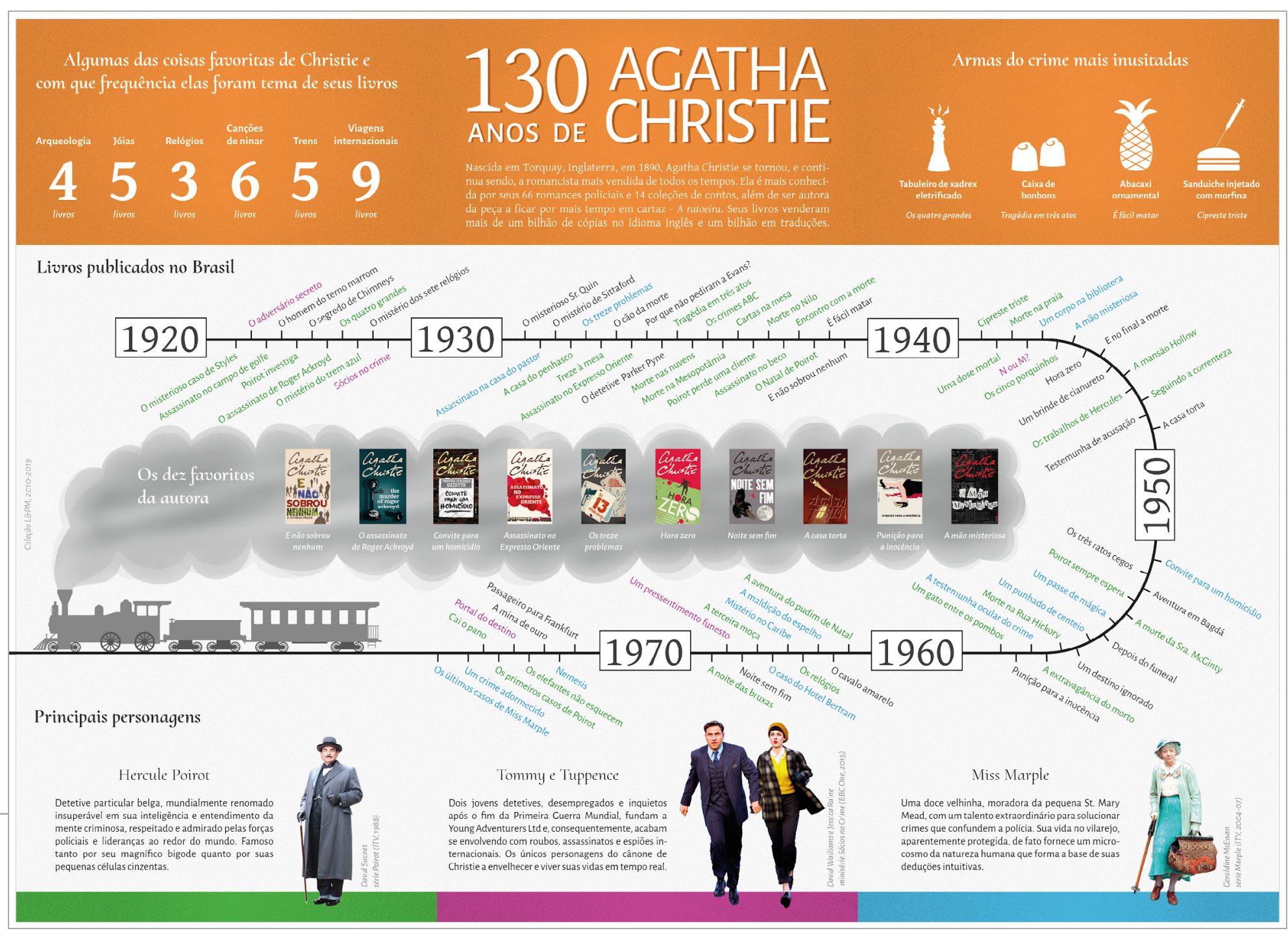


Foram selecionadas cores de uma harmonia cromática complementar mútua, na qual se encaixam os mesmos tons de laranja, verde e azul presentes nas capas dos livros e um tom próximo ao magenta. O infográfico foi dividido, através da cor, em duas áreas principais: uma faixa de cor laranja na porção superior da página, equivalente a uma quarta parte de sua altura e na porção inferior uma área de cor branca que possibilita um bom contraste com as informações textuais nela dispostas (AMBROSE; HARRIS, 2009).

$\mathrm{Na}$ faixa de cor laranja as informações são divididas em três blocos: no centro, o título do infográfico, 130 anos de Agatha Christie, acompanhado de um breve resumo sobre a autora e nas extremidades, duas seções que exibem curiosidades, através das quais são oferecidos vislumbres da personalidade da autora e de elementos de destaque em seus livros, assim, busca-se instigar o leitor a pesquisar mais sobre Christie e sua obra, fazendo com que este crie uma relação com o conteúdo oferecido, resultante de um processo reflexivo. Ainda, ao dispor dessas informações em um local de destaque na hierarquia visual teve-se a intenção de captar rapidamente o interesse no leitor, apostando em uma reação visceral.

$\mathrm{Na}$ área central, apresenta-se a linha do tempo com os títulos das obras organizados de modo a lembrar os trilhos do trem, interrompidos de quando em quando com as décadas, referenciando estações de trem, que começam em 1920, ano da primeira publicação de Agatha Christie, e terminam na ilustração de um trem que parte em direção à borda da página simbolizando 1976, ano da morte da autora. Através desse recurso divide-se uma informação numerosa em blocos menores facilitando sua compreensão. Buscou-se com essa representação mais uma maneira de aproximar o leitor da autora, uma vez que trens e viagens eram duas de suas coisas favoritas e aparecem recorrentemente em várias de suas histórias.

Ainda na porção central, a partir da fumaça que emana do trem, criou-se outra seção, na qual exibem-se os dez livros favoritos da autora, elegidos por ela própria em 1972. Através des- 
sa informação é oferecida ao leitor uma outra possível abordagem da obra de Christie, uma que evoca a memória da autora.

Na porção inferior da página, tem-se a apresentação dos personagens principais, que ocorre por meio das fotografias de atores que, em algum momento, os interpretaram, acompanhadas de pequenos textos, estes são separados visualmente por uma barra que estende-se horizontalmente pelo limite da página e indica uma cor para cada um. Nos títulos da linha do tempo utilizaram-se as mesmas cores como um sistema de codificação com o intuito de ajudar o leitor a identificar rapidamente quais livros são protagonizados por qual personagem (AMBROSE; HARRIS, 2009).

A divisão em seções e o uso de outros recursos que visam facilitar o entendimento das informações apresentadas tem grande importância para o nível comportamental pois objetiva-se que o leitor experiencie sem qualquer frustração o uso da peça gráfica desenvolvida. Da mesma forma, buscou-se apresentar a obra da autora sob diferentes pontos de vista, ao mesmo tempo que se estabelecem relações entre as seções do infográfico com o intuito de, para além de informar, entreter e motivar o leitor a ler os livros apresentados.

O infográfico, apresenta as medidas $420 \mathrm{~mm}$ de largura por $300 \mathrm{~mm}$ de altura, foi impresso à parte e quando dobrado longitudinalmente, em quatro, assume a função de cinta unindo os dois volumes da coleção. As dimensões do infográfico enquanto cinta são de $420 \mathrm{~mm}$ de largura por $75 \mathrm{~mm}$ de altura e seu fechamento é feito através de adesivo circular transparente com picote. Na Figura 11 pode-se observar imagens do projeto finalizado que exemplificam a relação do infográfico com os dois volumes da coleção. Essa configuração foi projetada para que, quando dobrado em formato de cinta e encaixado aos livros a parte central da faixa superior do infográfico, onde encontra-se o título, ficasse visível. 


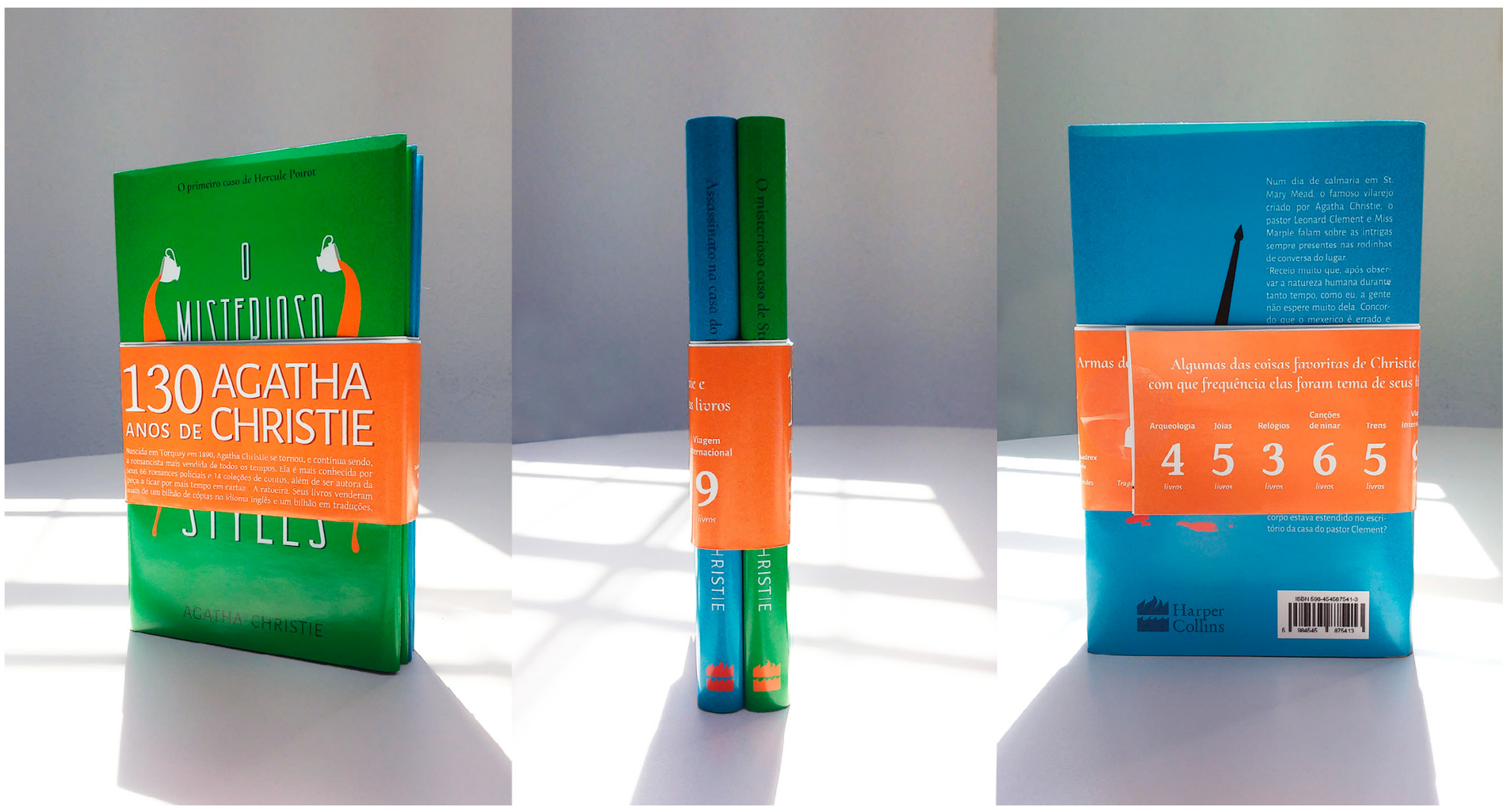

Figura 11 - Configuração do infográfico com relação aos livros. Fonte: dados da pesquisa.

\section{CONSIDERAÇÕES FINAIS}

A pesquisa dos campos teóricos abordados no trabalho, somado aos apontamentos reunidos com o breve levantamento de coleções, possibilitou explorar a obra da autora Agatha Christie, fomentando o planejamento e o desenvolvimento de um projeto prático. Através dele, buscou-se um olhar atual sobre a obra da autora, levando em consideração a influência dos meios digitais nas decisões de consumo, especialmente, do público jovem e a lógica de publicação do mercado editorial voltada para esse público.

As reflexões proporcionadas pelo estudo do design emocional permitiram avaliar que a relação do leitor com o livro vai além do conteúdo textual, pois esta reside também na materialidade dos volumes. Essa relação evidencia a importância do papel do designer, uma vez que é este o profissional responsável por dar forma, cor, dimensão e textura ao conteúdo intangível que é o texto literário. Para além disso, a atuação do designer pode transformar o sentido do texto ou reforçá-lo. 
Assim, a realização do trabalho garantiu a oportunidade de desenvolver o projeto completo, idealizando a proposta da coleção desde a seleção dos títulos, ocupando o papel que seria, muito provavelmente, do editor em uma coleção publicada. A leitura tanto da Autobiografia (c1977) da autora quanto daqueles títulos explorados na coleção desenvolvida possibilitou uma maior imersão em sua obra e refletiu positivamente no processo de criação.

De acordo com Norman (2008), um bom projeto de design é aquele que atua atendendo as necessidades dos três níveis: o visceral, o comportamental e o reflexivo, nesse sentido acredita-se que a prática projetual empreendida foi bem sucedida, uma vez que, a proposta da coleção de oferecer uma curadoria de títulos aliada à apresentação do infográfico que visa auxiliar o leitor na compreensão das produções literárias de Agatha Christie, promove o envolvimento do leitor com as obras da autora, deste modo criando uma experiência que atende ao nível reflexivo. Além disso, a coleção desenvolvida apresenta um resultado estético apelativo ao nível visceral, atraindo rapidamente a atenção por meio das cores utilizadas e o nível comportamental é contemplado através dos aspectos materiais que conferem ergonomia ao produto.

\section{REFERÊNCIAS BIBLIOGRÁFICAS}

\section{AGATHA CHRISTIE LTD. 2019. Agatha Christie Limited.}

Disponível em: https://www.agathachristielimited.

com/ . Acesso em: 26 set. 2019.

AMBROSE, Gavin; HARRIS, Paul. Cor.

Porto Alegre: Bookman, 2009.

CARVALHO, Ana Isabel Silva. A capa de livro: o objecto, o contexto, o processo. Porto: U.PORTO, 2008. Dissertação, Faculdade de Belas Artes, Universidade do Porto, 2008. 
CHERUBIN, Felipe. Fenômeno dos 'booktubers' difunde clássicos literários para público jovem. Estadão. 22 jul. 2017. Disponível em: https://alias.estadao.com.br/noticias/ geral,fenomeno-dos-booktubers-difunde-classicos-literariospara-publico-jovem,70001898464. Acesso em: 15 mai. 2019.

CHRISTIE, Agatha. Autobiografia. Rio de Janeiro: Record, c1977.

COLEÇÃO FOLHA O MELHOR DE AGATHA CHRISTIE. 2019. Disponível em: https://agathachristie.folha.com.br/. Acesso em: 26 set. 2019.

CURRAN, John. Os diários secretos de Agatha Christie: 50 anos de mistérios na criação. São Paulo: Leya, 2010.

DONDIS, Donis. Sintaxe da linguagem visual.

São Paulo: Martins Fontes, 1997.

FUENTES, Rodolfo. A prática do design gráfico: uma metodologia criativa. São Paulo: Edições Rosari, 2006.

GIL, Antonio Carlos. Métodos e técnicas de

pesquisa social. São Paulo: Atlas, 2008.

HASLAM, Andrew. 0 livro e o Designer II: como criar e produzir livros. São Paulo: Edições Rosari, 2010.

HUMPHERYS, Anne. British Detective Fiction in the 19th and Early 20th Centuries. Oxford Research Encyclopedia of Literature. Jun. 2017. Disponível em: https://oxfordre.com/ literature/abstract/10.1093/acrefore/9780190201098.001.0001/ acrefore-9780190201098-e-240. Acesso em: 13 set. 2019.

L\&PM. 2003-2019. Disponível em: https://www.

Ipm.com.br. Acesso em: 22 set. 2019.

LUPTON, Ellen. Novos fundamentos do

design. São Paulo: Cosac Naify, 2008.

MACHADO, Samir. Agatha Christie (Globo Livros). Sobre capas e demais coisas relacionadas ao design do livro. 15 fev. 2015a. Disponível em: http://sobrecapas. blogspot.com/2015/02/. Acesso em: 1 set. 2019. 
MACHADO, Samir. Agatha Christie (Nova Fronteira).

Sobre capas e demais coisas relacionadas ao design

do livro. 12 jul. 2015b. Disponível em: http://sobrecapas.

blogspot.com/2015/07/. Acesso em: 1 set. 2019.

MEGGS, Philip. História do design gráfico.

São Paulo: Cosac Naify, 2009.

MENEZES, Duda. Agatha Christie: por onde começar a ler? | book addict. 17 fev. 2019. (16m29s). Disponível em: https://youtu.be/BMXYDUrvR3s. Acesso em: 11 abr. 2019.

MELO, Chico Homem de (org.). O design gráfico

brasileiro: anos 60. São Paulo: Cosac \& Naify, 2006.

NORMAN, Donald. Design Emocional: por

que adoramos (ou detestamos) os objetos do

dia-a-dia. Rio de Janeiro: Rocco, 2008.

PRATES, Tito. Agatha Christie From my Heart: uma

Biografia de Verdades. Torres: Illuminare, 2016.

RODRIGUES, Bel. Agatha Christie: por qual livro devo começar a ler?. 16 mai. 2017. (5m07s). Disponível em: https://youtu.be/X9hji1Pkuv0. Acesso em: 11 abr. 2019.

RIBEIRO, Milton. Planejamento Visual

Gráfico. Brasília: LGE Editora, 2003.

SEHN, Thaís Cristina Martino. O livro como objeto de desejo. Pelotas: UFPEL, 2009. Monografia, Centro de Artes e Design, Universidade Federal de Pelotas, 2009.

TAUNTON, Matthew. Print culture. The British Library. 15

May. 2014. Disponível em: https://www.bl.uk/romantics-andvictorians/articles/print-culture. Acesso em: 13 set. 2019.

THE HOME OF AGATHA CHRISTIE. 2019. Disponível em: https://www.agathachristie.com/aboutchristie. Acesso em: 21 apr. 2019. 